\title{
Exploring Jolkinol D Derivatives To Overcome Multidrug Resistance in Cancer
}

\author{
Mariana A. Reis, ${ }^{\dagger, \| \odot ~ O m a r ~ B . ~ A h m e d, ~}{ }^{\dagger}$ Gabriella Spengler, ${ }^{\S}$ Joseph Molnár, ${ }^{\S}$ Hermann Lage, ${ }^{\ddagger, \perp}$ \\ and Maria-José U. Ferreira* ${ }^{*} \dagger$ \\ ${ }^{\dagger}$ Research Institute for Medicines (iMed.ULisboa), Faculty of Pharmacy, Universidade de Lisboa, Avenue Prof. Gama Pinto, 1649-003 \\ Lisbon, Portugal \\ ${ }^{\ddagger}$ Institute of Pathology, University Hospital Charité, 10117 Berlin, Germany \\ ${ }^{\S}$ Department of Medical Microbiology and Immunobiology, Faculty of Medicine, University of Szeged, Dóm tér 10, H-6720 Szeged, \\ Hungary
}

Supporting Information

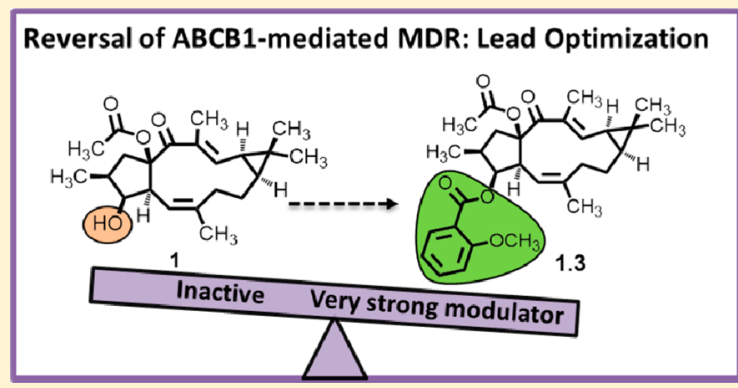

MDR-selective antiproliferative effect

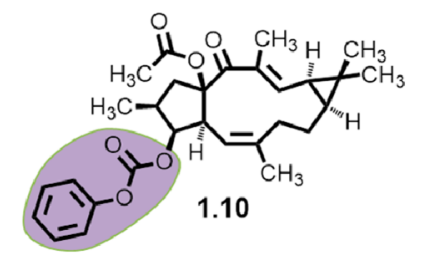

ABSTRACT: Macrocyclic monoacyl lathyrane derivatives bearing a benzoyl moiety were previously found to be strong ABCB1 modulators. To explore the effects of different substituents of the aromatic moiety, 14 new compounds $(1.1-1.7,1.10$, and 2.12.4) were prepared from jolkinol D (1), obtained from Euphorbia piscatoria, and from jolkinodiol (2), its hydrolysis derivative. Compounds 1.8 and 1.9, having aliphatic moieties, were also obtained. The reversal of ABCB1-mediated MDR was evaluated through functional and chemosensitivity assays on the human ABCB1-gene-transfected L5178Y mouse T-lymphoma cell line. Structure-activity relationships showed that addition of electron-donating groups to the aromatic moiety improved the activity. The effects on the ATPase activity of the strongest modulator (1.3) and the inactive jolkinol D (1) were also investigated and compared. Moreover, in the chemosensitivity assay, most of the compounds interacted synergistically with doxorubicin. Compounds 1.1-1.10 and 2.1-2.4 were further assessed for their collateral sensitivity effect against the human cancer cells: EPG85-257 (gastric) and EPP85-181 (pancreatic), and the matching drug-selected cells EPG85-257RDB, EPG85-257RNOV, EPP85-181RDB, and EPP85-181RNOV. The most promising ones (1.8 and 1.10) along with compound 3, previously selected, were investigated as apoptosis inducers. The compounds were able to induce apoptosis through caspase- 3 activation, with significant differences being observed between the parental and resistant cells.

$\mathrm{T}$ hroughout the world, cancer continues to be a leading cause of mortality. ${ }^{1}$ Despite the number of advances in this field, the development of resistance to anticancer drugs constitutes one of the main problems for a successful treatment. In the course of chemotherapy, multidrug resistance (MDR) is likely to occur, and as a result, tumors fail to respond to a broad spectrum of structurally and mechanistically diverse anticancer agents. ${ }^{2,3}$ A panoply of cellular resistance mechanisms related with an MDR cancer phenotype have been identified; one of the most widely studied involves the transmembrane $A B C$ transporter P-glycoprotein (P-gp/ABCB1). ${ }^{4-6}$ In normal cells, this efflux pump takes part in the natural detoxifying system, recognizing xenobiotics and extruding them from the cytosol. However, in cancer cells, ABCB1 overexpression causes a reduction of the cytosolic concentration of the anticancer agent. This will lead to a treatment failure resulting in cross-resistance to several cytotoxic drugs, such as cisplatin, colchicine, vinblastine, paclitaxel, doxorubicin, and protein kinase inhibitors. ${ }^{6}$ The improvement of chemotherapies targeted to overcome cancer MDR holds promise for a selective and efficient cancer treatment. Promising strategies to accomplish that purpose depend on the research of molecules capable of lessening the ABCB1 drug efflux, and the discovery of compounds with collateral sensitivity activity. ${ }^{7,8}$

The collateral sensitivity effect was first observed in bacteria, but nowadays it is being used as a powerful asset to study cancer MDR. ${ }^{8,9}$ In resistant cancer cells, each genomic, proteomic, or metabolomic alteration that conferred advantages during chemotherapeutic pressure might be at the same time a

Received: November 21, 2016

Published: April 19, 2017 
way to create vulnerabilities. The collateral sensitivity effect approach takes advantage of these vulnerabilities, converting them into new therapeutic targets. ${ }^{8,10,11}$ Consequently, drugresistant phenotypes can be more sensitive to alternate agents than the original parental cell line. ${ }^{8,11}$ As a result, highly selective compounds can be found and characterized.

Anticancer drug discovery programs are increasing their interest in natural products. ${ }^{12}$ Nature presents a vast chemical space that was selected through evolution to interact with a wide range of biological targets. Therefore, it is not surprising why natural compounds and their derivatives have become effective anticancer drugs. ${ }^{13}$ Owing to the fast pace of development of drug resistance, a growing chemical space is needed. In this regard, Euphorbia macrocyclic diterpenoids of the jatrophane- and lathyrane-type have shown significant MDR reversal activity, by $A B C B 1$ modulation and/or by selective targeting of MDR cancer cells. These promising results guide us to the development of in silico studies, and structure activity studies for optimizing their structures in order to develop an effective MDR reversal agent. ${ }^{14-19}$ Despite this progress, understanding their anti-MDR mode of action is still lacking.

In a previous report, we discussed a small library of jolkinol $\mathrm{D}$ derivatives in order to study the impact of structural modifications on $\mathrm{ABCB} 1$ efflux modulation. It was concluded that the presence of an aromatic moiety improved the inhibition of this efflux pump at noncytotoxic doses. ${ }^{20}$ Moreover, these derivatives were evaluated for their collateral sensitivity effects, of which jolkinoate L (3, Figure 1) displayed

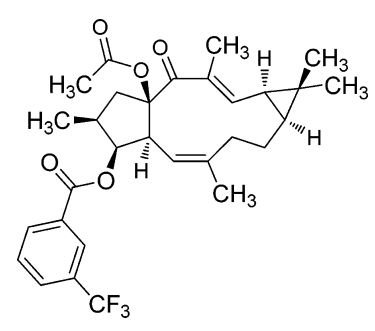

Figure 1. Jolkinoate L (3).

an interesting MDR-selective antiproliferative activity. ${ }^{21}$ In the sequence of this anti-MDR development project, we optimized jolkinol D (1) and jolkinodiol (2) scaffolds by generating a new set of derivatives (1.1-1.10 and 2.1-2.4) in order to obtain a higher MDR reversal effect. This was assessed through the combination of ABCB1 modulation and collateral sensitivity effects. Thus, compounds $\mathbf{1 . 1 - 1 . 1 0}$ and $\mathbf{2 . 1 - 2 . 4}$ were tested for their ability to modulate the drug efflux activity of ABCB1 and to resensitize MDR cells to doxorubicin in drug combination studies, using $\mathrm{ABCB} 1$-transfected mouse $\mathrm{T}$ lymphoma L5178Y cells. The type of interaction with the ATPase function of ABCB1 was also investigated for the parent molecule (1) and the strongest modulator (1.3). The MDRselective antiproliferative activity was assayed using the human tumor gastric (EPG85-257) and pancreatic (EPP85-181) cell models (drug-sensitive and drug-resistant sublines), well characterized for $\mathrm{MDR}^{21-23}$ The most promising derivatives $(1.8,1.10)$, and jolkinoate $\mathrm{L}(3)$, were investigated for their potential as apoptosis inducers.

\section{RESULTS AND DISCUSSION}

Chemistry. The previous structure-activity relationship (SAR) analysis of jolkinol D (1) derivatives showed that ABCB1 efflux modulation was enhanced when an aromatic ester moiety was added to the lathyrane scaffold. ${ }^{20}$ However, the role of aromatic electronic effects as well as hindrance effects on ABCB1 efflux activity was still to be investigated. As a result, a new set of derivatives (1.1-1.10 and 2.1-2.4) was generated. Jolkinoates $\mathrm{J}-\mathrm{T}(\mathbf{1 . 1}-\mathbf{1 . 7})$ were obtained by reaction of jolkinol D (1), isolated from Euphorbia piscatoria Ait. (Euphorbiacae), ${ }^{20}$ with the respective aroyl chlorides in the presence of $\mathrm{CH}_{2} \mathrm{Cl}_{2}$, TEA, and DMAP (Scheme 1). In parallel, to study the role of the free hydroxy group at $\mathrm{C}-15$, jolkinolates A-D (2.1-2.4) were prepared using jolkinodiol (2) ${ }^{20}$ as parent molecule (Scheme 1). Moreover, an adamantane derivative (1.8) and two carbonate esters, one aliphatic (1.9) and one aromatic (1.10), were also synthesized (Scheme 2), using silver triflate ${ }^{24}$ as catalyst. The structures of the derivatives were assigned by $1 \mathrm{D}$ and $2 \mathrm{D}$ NMR and HRMS data. The ${ }^{1} \mathrm{H}$ and ${ }^{13} \mathrm{C}$ NMR data of compounds 1.1-1.10 and 2.1-2.4 were compared with those of jolkinol D (1) and jolkinodiol (2), respectively. As expected, the main differences were found for $\mathrm{C}-3$ and $\mathrm{H}-3$, which showed paramagnetic effects in carbon and proton chemical shifts $(\Delta \delta \mathrm{C} \cong 0.2-6.4$ and $\Delta \delta \mathrm{H} \cong 1.1-1.9 \mathrm{ppm})$, due to the presence of the ester function. The $\beta$-carbons of the acyl derivatives (C-2 and C-4) also showed the anticipated diamagnetic effects $(\Delta \delta \mathrm{C} \cong 0.8$ and 0.6-1.4 ppm, respectively).

ABCB1-MDR Reversal Activity. In order to compare with the previous results, the same experimental design ${ }^{20}$ was followed. The antiproliferative activity of the compounds was assayed against the parental mouse T-lymphoma cells (L5178YPAR), and the $A B C B 1$-transfected counterpart (L5178YMDR), using the MTT assay. The derivatives 1.1-1.10 and 2.1-2.4 did not show a significant antiproliferative profile $\left(\mathrm{IC}_{50}\right.$ $>19 \mu \mathrm{M}$ ) for both cell lines (Table S1).

Modulation of $A B C B 1$ efflux was tested using the standard rhodamine-123 functional assay. Whether a compound modulates ABCB1 efflux or not is given by the fluorescence activity ratio (FAR). This ratio represents the accumulation of rhodamine-123 between L5178Y-MDR and L5178Y-PAR cells. Modulation of ABCB1 is considered to occur when FAR values are higher than one. Strong modulation of this transporter occurs when this ratio is higher than $10 .^{25}$ The derivatives 1.11.10 and 2.1-2.4 were tested at 2 and $20 \mu \mathrm{M}$ (nontoxic concentrations), and verapamil, a standard modulator, was used as positive control. When tested at $20 \mu \mathrm{M}$, all the lathyrane derivatives $(1.1-1.10 ; 2.1-2.4)$ caused a strong impairment of ABCB1 efflux activity, with FAR values ranging from 9.9 to 41.5 (Table 1). The strongest modulators of this library were depicted based on the $2 \mu \mathrm{M}$ data (Table 1 ). Thus, the most efficient modulators were the jolkinol $\mathrm{D}$ derivatives 1.2, 1.3, 1.5-1.8, and 1.10 and the jolkinoldiol derivative 2.1 (FAR values from 10.8 to 33.3 ). These results are interesting because the ABCB1 reversal activity of verapamil $(22 \mu \mathrm{M})$ was 12.5 .

Structure-Activity Relationships. The K-means clustering algorithm was used to highlight some of the possible relations between $\mathrm{ABCB} 1$ modulatory activity and the calculated physicochemical features. As a result, four groups sharing a high degree of similarity, in terms of physicochemical properties and activity at $2 \mu \mathrm{M}$, were generated (Figure 2 ). The first cluster grouped the derivatives with the bulkier 
Scheme 1. Preparation of Jolkinoates N-T (1.1-1.7) and Jolkinolates A-D (2.1-2.4) ${ }^{a}$

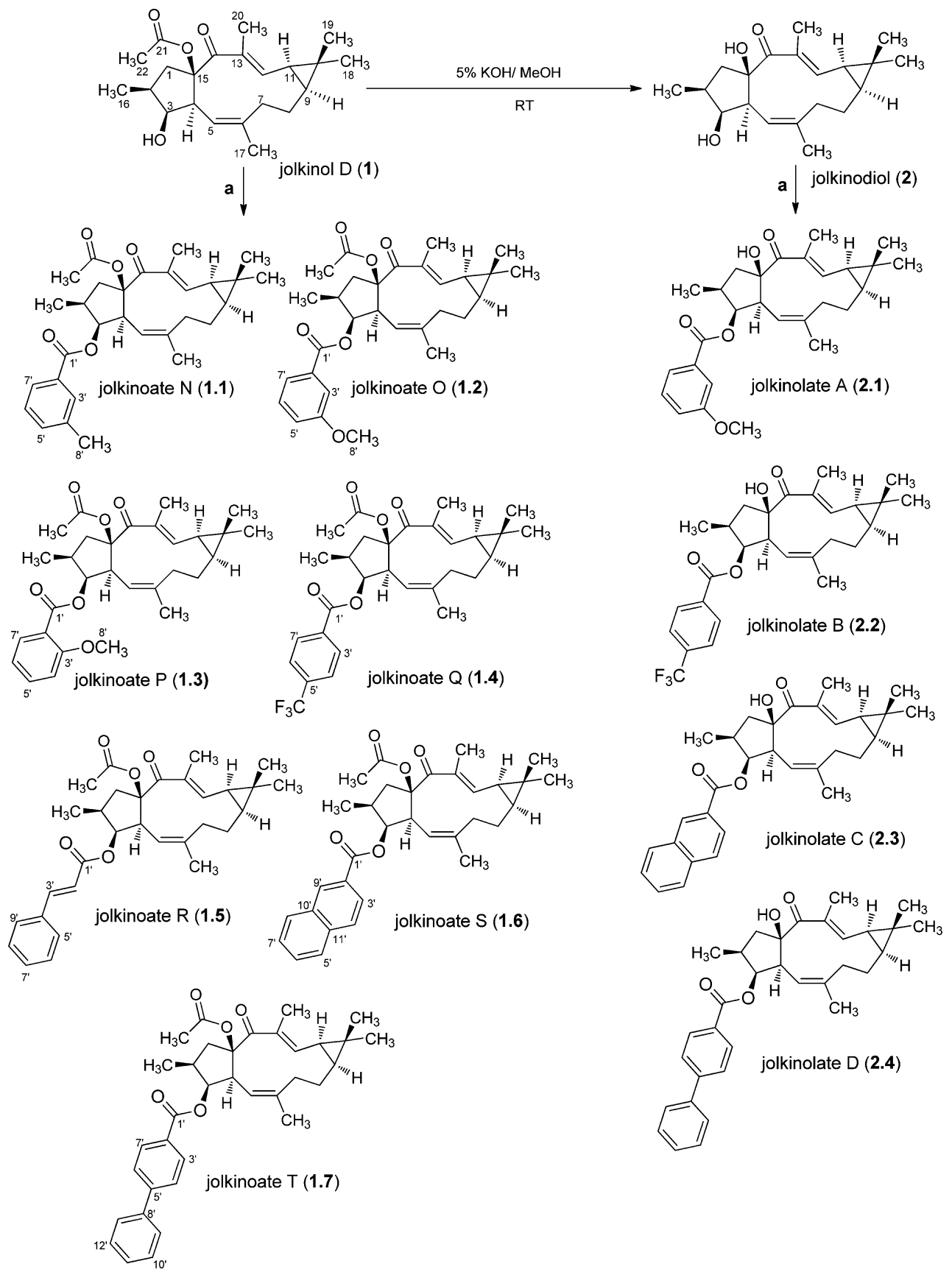

${ }^{a}$ Reagents and conditions: 1 equiv of jolkinol D (1); 1 equiv of jolkinodiol (2); (i) Respective aroyl chlorides; TEA, $\mathrm{CH}_{2} \mathrm{Cl}_{2}, \mathrm{DMAP}_{\text {(cat.) }}$, reflux 60 ${ }^{\circ} \mathrm{C}$.

substituents (1.4, 1.6, 1.7, 1.8, and 2.4), therefore showing the highest MW, MV, logP, MR, and ASA values (Figure 2). The strongest $A B C B 1$ modulators 1.2, 1.3, and 1.5 were grouped mainly due to the FAR values, since their physicochemical properties are shared by compounds in clusters I and III (Figure 2). Cluster III comprised the jolkinodiol derivatives 2.1-2.3 as well as compounds 1.1 and 1.10. Jolkinocarbonate A (1.9) occupied cluster IV. Nevertheless, contrary to what was described for the first set of jolkinol D derivatives, ${ }^{20}$ no significant correlations were found between the computed physicochemical properties and $\mathrm{ABCB} 1$ modulatory activity. This can be suggestive of a stronger role of the sum of other structural aspects, than the contribution of a single physicochemical property. In fact, a recent in silico study, through $2 \mathrm{D}$ and $3 \mathrm{D} \mathrm{Q}$ (quantitative)SAR, concluded that the conformation of the lathyrane macrocyclic scaffold and its substitution pattern (related to steric and electrostatic factors) were the main determinants for the ABCB1 modulation activity. ${ }^{19}$

Therefore, to investigate the former observations, attention was focused on the SAR of esters containing the aromatic moiety; in this way, we compared the previous results ${ }^{20}$ with those described herein. Thus, in comparison to jolkinoate $\mathrm{I}^{20}$ bearing an unsubstituted aroyl moiety $(\mathrm{FAR}=24.2)$, the introduction of trifluormethyl, an electron-withdrawing group, at the meta or para positions of the benzene moiety, lead to a 
Scheme 2. Preparation of Jolkinoate $U(1.8)$ and Jolkinocarbonates A and B $(1.9-1.10)^{a}$

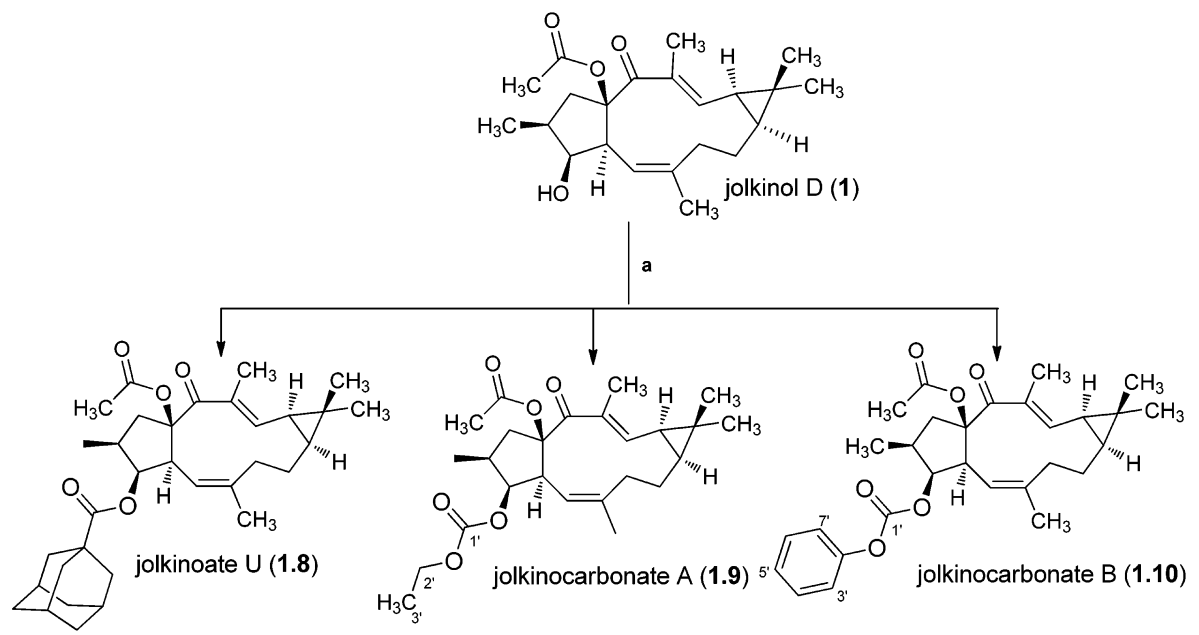

${ }^{a}$ Reagents and conditions: 1 equiv of jolkinol D (1); (a) Respective chlorides; AgOTF ( 1 mol \%), $\mathrm{CH}_{2} \mathrm{Cl}_{2}$, reflux $60{ }^{\circ} \mathrm{C}$.

Table 1. Modulation of ABCB1-Mediated Rhodamine-123 Efflux by Jolkinol D Derivatives 1.1-1-10 and Jolkinodiol Derivatives $2.1-2.4$

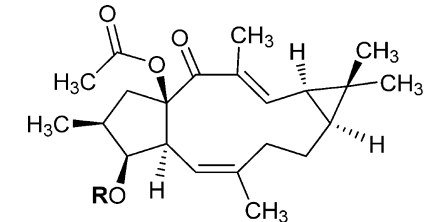

FAR $^{a}$

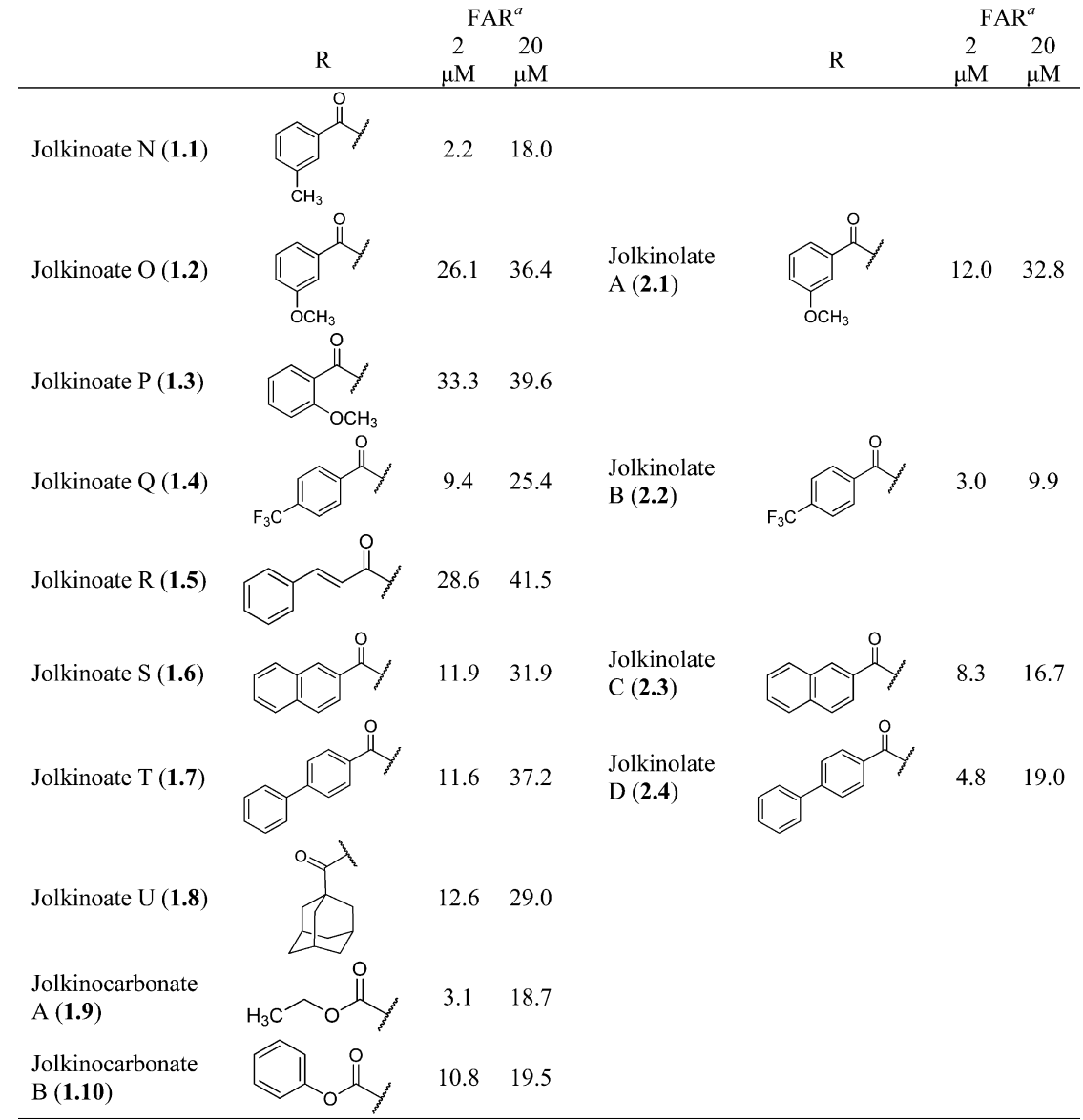

${ }^{a} \mathrm{FAR}=\left(\mathrm{L} 5178 \mathrm{Y}-\mathrm{MDR}_{\mathrm{FL}-1 \text { treated }} / \mathrm{L} 5178 \mathrm{Y}-\mathrm{MDR}_{\mathrm{FL}-1 \text { control }}\right) /\left(\mathrm{L} 5178 \mathrm{Y}-\mathrm{PAR} \mathrm{FL}_{\mathrm{FL}-1 \text { treated }} / \mathrm{L} 5178 \mathrm{Y}-\mathrm{PAR}_{\mathrm{FL}-1 \text { control }}\right)$. FL-1: mean fluorescence intensity of the cells. Verapamil $(22 \mu \mathrm{M}) \mathrm{FAR}=12.5$. DMSO $(2 \%) \mathrm{FAR}=0.87$. 

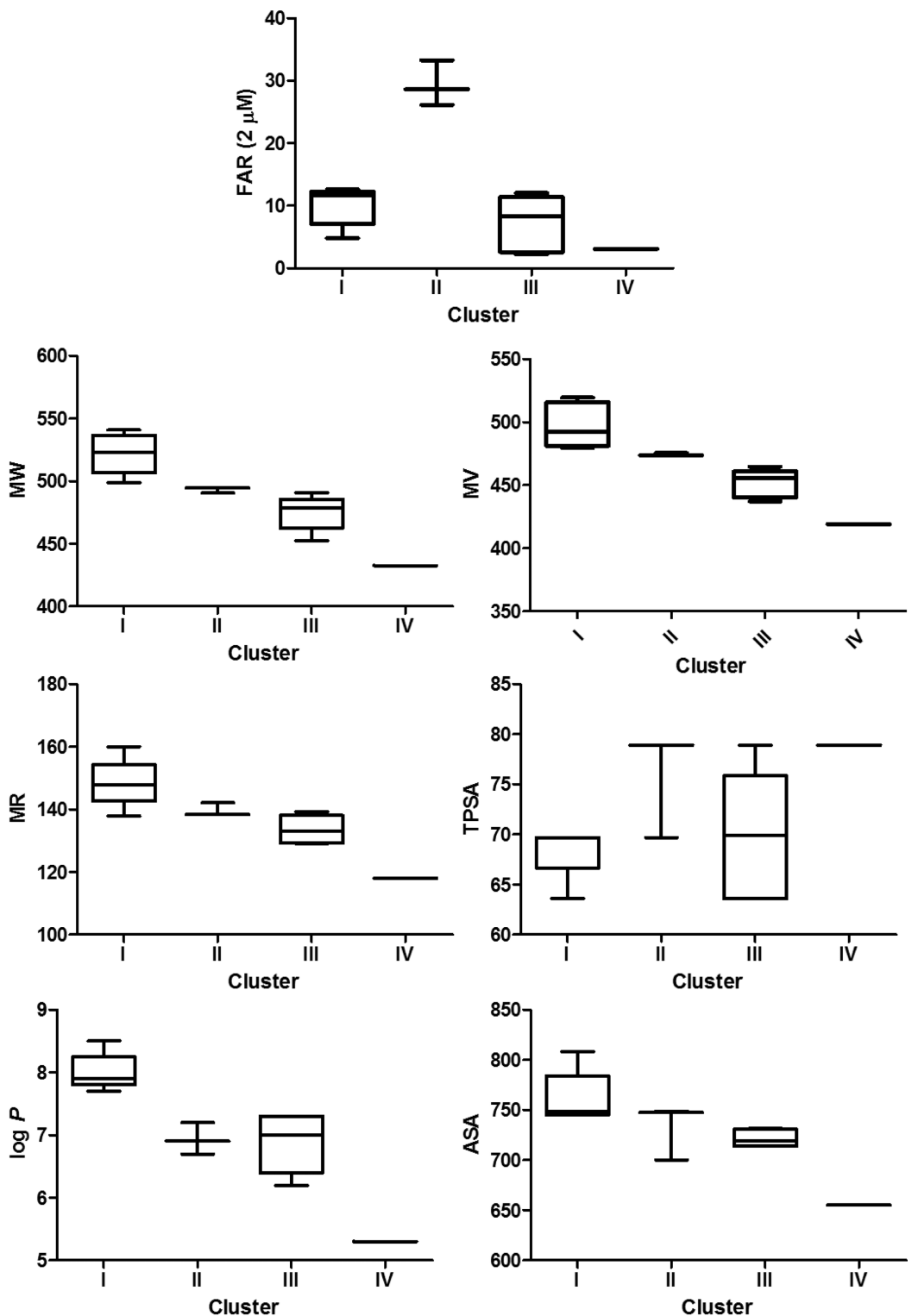

Figure 2. Cluster analysis of compounds 1.1-1.10 and 2.1-2.4. Box and whiskers plot representing each grouping variable: FAR values (2 $\mu \mathrm{M})$, molecular weight $(\mathrm{MW})$, molecular volume $(\mathrm{MV}), \log P$ prediction developed at Molinspiration $(\log P)$, molar refractivity (MR), topological polar surface area (TPSA), and accessible solvent area (ASA). Physicochemical properties were calculated using JME molecular editor, version July 2016, http://www.molinspiration.com/jme.

decreased efflux modulatory efficiency [(2.5-fold) FAR $=9.3$ and 9.4, respectively to jolkinoate $\mathrm{L}^{20}$ and 1.4]. Likewise, jolkinocarbonate B $(1.10 ;$ FAR $=10.8)$ with a phenyl substituent, lost modulatory ability in comparison to jolkinoate I. Jolkinoate $\mathrm{N}(\mathbf{1 . 1}$; FAR $=2.2)$, displaying an $m$-methyl group, was nearly inactive. However, jolkinoate $\mathrm{J}{ }^{20}$ possessing this moderate electron-donating group at the para position, retained a strong modulatory character $($ FAR $=21.1)$. The effects of a strong electron-donating group were investigated by using the methoxy group; nevertheless, differences in activity were not significant. Incorporation of this group at the ortho (1.3; FAR = 33.3) and para (jolkinoate $\mathrm{K}$; FAR $=28.1)^{20}$ positions seemed to have a slightly higher electronic influence due to the resonance effects than its regioisomer at the meta position (1.2; $\mathrm{FAR}=26.1)$. Moreover, jolkinoate $\mathrm{R}(1.5 ; \mathrm{FAR}=28.6)$, bearing a cinnamoyl moiety, was also among the strongest modulators, suggesting that the aromatic conjugated system is a contributor toward $\mathrm{ABCB} 1$ modulation.
The potential steric hindrance on $\mathrm{ABCB} 1$ efflux modulation was studied by inclusion of bulky groups such as naphthoyl (1.6; FAR = 11.9), biphenoyl (1.7; FAR = 11.6), and adamantoyl $(1.8 ;$ FAR $=12.6)$. The 2 -fold reduction of modulatory efficiency, when compared to jolkinoate I (FAR = $24.2){ }^{20}$ suggests that introduction of a bicyclic moiety potentiates steric clashes within the drug-binding pocket of $\mathrm{ABCB} 1$, independently from its aromatic nature. Similar observations were found by Jiao and co-workers, which verified that lathyrol derivatives with 1-naphthylacetyl or phenylacetyl substituents lost ABCB1 modulatory ability. ${ }^{26}$

Furthermore, some derivatives of jolkinodiol (2) were included to test the role of a free hydroxy group at C-15. Jolkinolate A (2.1), bearing a 3-methoxybenzoyl moiety at C-3, showed a 2-fold loss in efficacy in comparison to jolkinoate $\mathrm{O}$ (1.2), where the hydroxy group at C-15 is acetylated. The same tendency was observed for the jolkinoldiol derivatives 2.2, 2.3, and 2.4 in comparison to their respective counterparts 1.4, 1.6, 
and $\mathbf{1 . 7}$ (Table 1). Thus, the presence of the acetyl group at C15 as a hydrophobic center or hydrogen-bond acceptor moiety might be more important for recognition/interaction with $A B C B 1$ than the presence of a hydrogen-bond donor. These findings are in accordance with the in-house pharmacophore model, based on macrocyclic diterpenoids and other ABCB1 inhibitors, in which the recognition pattern contains three hydrophobic moieties and one hydrogen-bond acceptor group. ${ }^{14}$

In conclusion, with this SAR study a favorable optimization for jolkinoates as ABCB1 modulators was achieved. Benzoyl moieties with electron-donating groups should increase the electrostatic interactions and $\pi$-stacking at the drug-binding pocket of $A B C B 1$, resulting in a more powerful $A B C B 1$ efflux modulation.

Effects on the ATPase Activity of ABCB1. ATP hydrolysis is linked with the ABCB1 efflux activity. ${ }^{27,28}$ The way how compounds affect this catalytic activity can give insights about their properties as substrate or inhibitor. Therefore, the effects on the ATPase activity of this membrane transporter were evaluated for the parent compound jolkinol D (1) and the most active modulator of this set of lathyranes, jolkinoate $\mathrm{P}$ (1.3). This activity was assessed through the production of inorganic phosphate directly resulting from the ATP hydrolysis of human ABCB1 expressed in purified insect membrane vesicles (Sf9). Vanadate is a phosphate analogue that inhibits $\mathrm{ABCB} 1$ ATPase activity; therefore, the results obtained are presented as the vanadate sensitive ATPase activity. This ATPase experiment is composed of two complementary assays. The activation assay classifies compounds as stimulators or inhibitors of the baseline vanadate sensitive ATPase activity. The inhibition assay, performed in the presence of a known ABCB1 activator, is used to characterize efflux inhibitors (or slowly transported substrates) through the decrease of verapamil-stimulated vanadate-sensitive ATPase activity. Verapamil $(40 \mu \mathrm{M})$ and cyclosporin A (40 $\mu \mathrm{M})$ were used as positive controls in the activation and inhibition assays, respectively. Jolkinol D (1) and jolkinoate P (1.3) were tested in a dose-dependent manner, and the effects were shown as the relative ATPase activity, in which the stimulated vanadate-sensitive ATPase activity is taken as $100 \%$ and the baseline vanadate-sensitive ATPase activity as $0 \%$.

Jolkinol D (1) enhanced the basal ATPase activity with 66$87 \%$, though this stimulation was not dose dependent (Figure $3 \mathrm{~A}$, activation assay). These findings indicate that compound 1 interacts with the membrane transporter $\mathrm{ABCB} 1$. Concerning the verapamil-stimulated ATPase activity, jolkinol D (1) showed an inhibitory effect of $14-40 \%$, in the range 3.13$12.5 \mu \mathrm{M}$ (Figure 3A, inhibition assay). At higher concentrations (25-100 $\mu \mathrm{M})$, compound (1) showed 9-33\% stimulation of the verapamil-stimulated ATPase activity (Figure 3A, inhibition assay). The results from this ATPase assay suggest jolkinol D (1) to be a transported substrate of $A B C B 1$, which at some concentrations can affect verapamil transport (inhibition or stimulation). Nevertheless, it should be noted that jolkinol D (1) did not affect ABCB1 efflux at 2 or $20 \mu \mathrm{M}^{20}$

Interesting results were obtained with the strong modulator jolkinoate $\mathrm{P}$ (1.3). The direct interaction with $\mathrm{ABCB} 1$ is shown through the activation of the ATPase activity (Figure 3B, activation assay). This activation occurred to a lower extent compared to jolkinol D (1). Moreover, at higher doses (>50 $\mu \mathrm{M})$, jolkinoate $\mathrm{P}$ (1.3) inhibited ABCB1 ATPase activity. This type of dose-dependent activation of ATPase activity at low
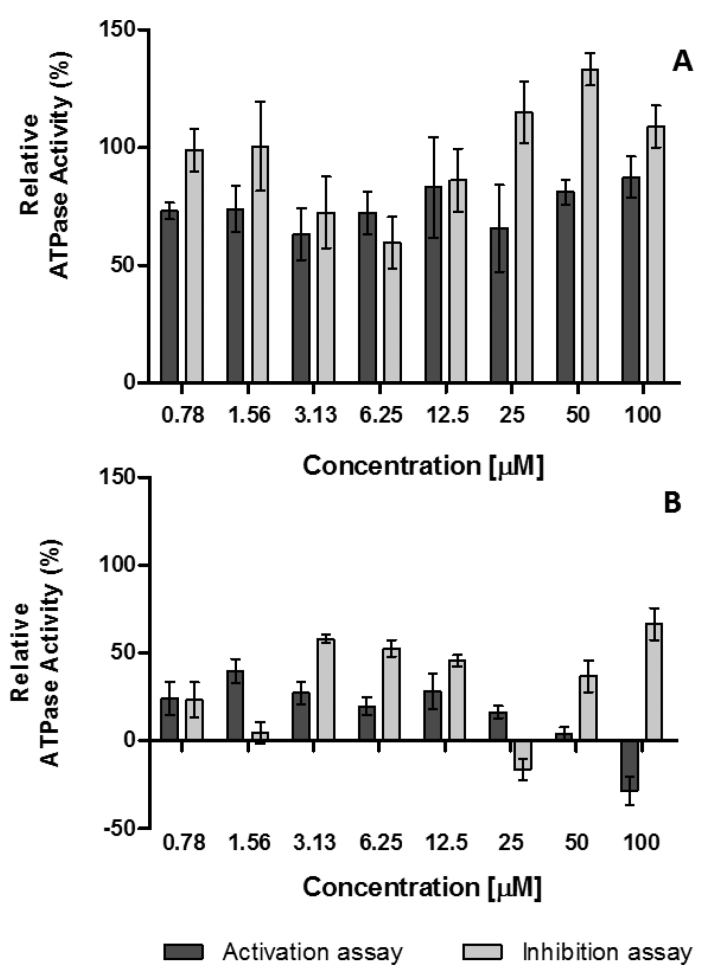

Figure 3. Effects of (A) jolkinol D (1) and (B) jolkinoate P (1.3) on ABCB1 ATPase activity. Activation assay: tests the effect on the basal ATPase activity. Inhibition assay: tests the effect on drug-stimulated ATPase activity, measured in the presence of verapamil $(40 \mu \mathrm{M})$. Results are expressed as the mean $\pm \mathrm{SD}$. The effects of compounds are shown as the relative ATPase activity, in which the verapamilstimulated vanadate-sensitive ATPase activity is taken as $100 \%$ and the baseline vanadate-sensitive ATPase activity as $0 \%$.

concentrations and inhibition at higher concentrations was observed for several compounds. ${ }^{29,30}$ Recently, a conformationally gated model of drug-induced activation of ABCB1mediated ATP hydrolysis was established to study this issue. ${ }^{30}$ According to this model, when verapamil occupies the $\mathrm{H}$-site of the ABCB1 drug-binding pocket, ATP hydrolysis and transport are maximized at low concentrations of verapamil. When verapamil is present in high concentrations, it occupies both the $\mathrm{H}$-site and a low affinity binding site; due to this, the protein is stabilized into an "intermediate" conformation that prevents ATP from driving ABCB1 to the "closed" conformation. Consequently, the verapamil transport and verapamil-stimulated ATP hydrolysis are reduced. These findings might help to understand the jolkinoate $\mathrm{P}$ (1.3) dose effect on the ABCB1 ATPase activity.

When tested concomitantly with a second substrate, jolkinoate $\mathrm{P}$ (1.3) was able to diminish the verapamilstimulated ATPase activity, with a complete inhibition at 1.56 and $25 \mu \mathrm{M}$ (Figure $3 \mathrm{~B}$, inhibition assay). This indicated that jolkinoate $\mathrm{P}$ (1.3) was capable of ceasing the transport of verapamil, through direct interaction with $\mathrm{ABCB}$. Moreover, the inhibition assay also suggested jolkinoate $\mathrm{P}(1.3)$ to elicit a biphasic dose response on the ABCB1 ATPase. This biphasic nature was observed for some compounds and might be attributed to the polyspecificity of ABCB1 drug-binding sites. ${ }^{31}$ Verapamil and rhodamine-123 have different binding sites within the drug-binding pocket of $\mathrm{ABCB} 1 .^{32,33}$ Relating the results obtained in this work, it can be suggested that compound 1.3 might act as a modulator and/or a slowly 
transported substrate affecting the transport of these two molecules.

Chemosensitization: Reversion of Drug-Induced Resistance. In order to test if the lathyrane derivatives would turn L5178Y-MDR cells more susceptible to anticancer drug action, their combinations with doxorubicin were tested. The nature of the drug interactions was determined by the combination index (CI) as synergistic, additive, or antagonistic (Table 2). ${ }^{34,35}$ Apart from jolkinoates $\mathrm{R}$ (1.5) and U (1.8), and

Table 2. Drug Combination Experiments in ABCB1Transfected Mouse T-Lymphoma Cells (L5178Y-MDR)

\begin{tabular}{|c|c|c|c|}
\hline $\begin{array}{l}\text { Combination with } \\
\text { Doxorubicin }\end{array}$ & Ratio $^{a}$ & $\mathrm{CI} \pm \mathrm{SD}^{b}$ & Interaction \\
\hline Jolkinoate O (1.2) & $25: 1$ & $0.84 \pm 0.14$ & moderate synergisn \\
\hline Jolkinoate P (1.3) & $10: 1$ & $0.09 \pm 0.03$ & $\begin{array}{r}\text { very strong } \\
\text { synergism }\end{array}$ \\
\hline Jolkinoate R (1.5) & $50: 1$ & $1.13 \pm 0.37$ & slight antagonism \\
\hline Jolkinoate S (1.6) & $400: 1$ & $0.06 \pm 0.02$ & $\begin{array}{l}\text { very strong } \\
\text { synergism }\end{array}$ \\
\hline Jolkinoate $\mathrm{T}(\mathbf{1 . 7})$ & $100: 1$ & $0.32 \pm 0.08$ & synergism \\
\hline Jolkinoate U (1.8) & $15: 1$ & $1.11 \pm 0.37$ & slight antagonism \\
\hline Jolkinocarbonate A (1.9) & $5: 1$ & $1.22 \pm 0.28$ & $\begin{array}{l}\text { moderate } \\
\text { antagonism }\end{array}$ \\
\hline Jolkinocarbonate B (1.10) & $18: 1$ & $0.50 \pm 0.07$ & synergism \\
\hline Jolkinolate A (2.1) & $50: 1$ & $0.38 \pm 0.16$ & synergism \\
\hline Jolkinolate C (2.3) & $200: 1$ & $0.20 \pm 0.05$ & strong synergism \\
\hline
\end{tabular}

${ }^{a}$ Data are shown as the best combination ratio of the tested compounds and doxorubicin. ${ }^{b}$ Combination index (CI) values are mean \pm standard deviation (SD) for an inhibitory concentration of $50 \%\left(\mathrm{IC}_{50}\right)$. CI $<0.1$ : very strong synergism; $0.1<\mathrm{CI}<0.3$ : strong synergism; $0.3<\mathrm{CI}<0.7$ : synergism; $0.7<\mathrm{CI}<0.9$ : moderate to slight synergism; $0.9<\mathrm{CI}<1.1$ : nearly additive; $1.10<\mathrm{CI}<1.45$ : moderate antagonism; $1.45<\mathrm{CI}<3.30$ : antagonism. ${ }^{34,35}$ Compounds 1.1, 1.4, 2.2, and 2.4 are not assayed due to $\mathrm{IC}_{50}>80 \mu \mathrm{M}$.

jolkinocarbonate A (1.9), that showed an antagonistic effect on the combination assay ( $\mathrm{CI}=1.11-2.02$, Table 2$)$, the remaining derivatives improved the cytotoxicity of doxorubicin synergistically $(\mathrm{CI}=0.20-0.84)$. The modulators were able to restore sensitivity to doxorubicin by reversing the $A B C B 1$ MDR phenotype.

Collectively the results from the transport (Table 1) and drug combination assays (Table 2) showed that the tested resistance modulators were able to affect $A B C B 1$ efflux activity and to restore sensitivity to doxorubicin (except compounds 1.5, 1.8, and 1.9). This is an interesting finding because the cytotoxic efficacy of doxorubicin is known to be affected by ABCB1 activity. ${ }^{6,36}$ Moreover, it is interesting to note that, although jolkinoates $\mathrm{R}(\mathbf{1 . 5})$ and $U$ (1.8) were strong ABCB1 modulators at $2 \mu \mathrm{M}$, they displayed antagonistic effects in the combination experiments. These compounds might be targeting other cellular pathways and, thus, may antagonize the doxorubicin effect by competing or inhibiting its targets, independently from interaction with $\mathrm{ABCB} 1$.

Conversely, jolkinol D (1), a non-ABCB1 modulator, showed a synergistic effect with doxorubicin. ${ }^{20}$ Recalling the nature of interaction with ATPase, jolkinol D (1) was qualified as a transported substrate, and this result might contribute to explaining why the combination between this nonmodulator and the cytotoxic drug showed a synergistic nature. ${ }^{20}$ Therefore, this compound might have more affinity or compete with doxorubicin for ABCB1 transport, suggesting accumulation of doxorubicin to the detriment of jolkinol D (1) efflux.
Collateral Sensitivity Effect. In a preceding study, some jolkinol D derivatives were assessed for their potential selective antiproliferative activity against parental gastric (EPG85-257) and pancreatic (EPP85-181) human cancer cells and their drugresistant counterparts, selected against mitoxantrone (RNOV) or daunorubicin (RDB), respectively, using a proliferation assay. $^{21}$ Most of those derivatives exhibited selective antiproliferative activity effects toward the EPG85-257RDB cell line. However, jolkinoate L (3) showed a remarkable ability to target different cellular contexts with concomitant high antiproliferative activity. ${ }^{21}$ As a continuation of this development program, herein compounds $\mathbf{1 . 1 - 1 . 1 0}$ and $\mathbf{2 . 1 - 2 . 4}$ were investigated for their potential collateral sensitivity effect on the same cancer entities (Tables S2 and S3, Supporting Information).

The MDR-selective activity was assessed by the relative resistance ratio $\left(\mathrm{RR}=\mathrm{IC}_{50 \text { (resistant) }} / \mathrm{IC}_{50 \text { (parental) })}\right) . \mathrm{RR}<1$ indicates that the compound kills MDR cells more effectively than parental cells, but if $R R<0.5$, a collateral sensitivity effect is taking place. ${ }^{10}$ The cytotoxic agents etoposide and cisplatin were used as positive controls. The antiproliferative activity and collateral sensitivity effects of compounds $\mathbf{1 . 1 - 1 . 1 0}$ and 2.12.4 are shown as a heat map table (Table 3). This

Table 3. Heat Map Table Summarizing the Antiproliferative and Collateral Sensitivity Results against Gastric Carcinoma Cells (EPG85-257P, EPG85-257RNOV, and EPG85257RDB) and Pancreatic Carcinoma Cells (EPP85-181P, EPP85-181RNOV, and EPP85-181RDB) ${ }^{a}$

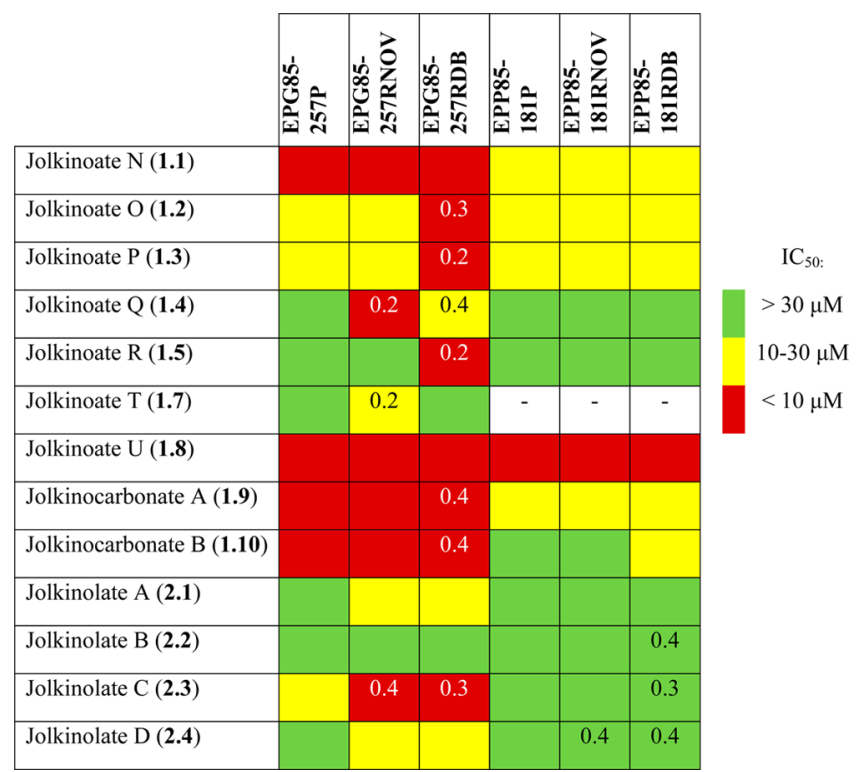

${ }^{a_{T}}$ This representation permits identifying compounds that show MDRselective activity at a determined $\mathrm{IC}_{50}$ sevel. Collateral sensitivity values $(\mathrm{RR}<0.5)$ are shown.

representation enables the identification of compounds that show MDR-selective activity at a determined $\mathrm{IC}_{50}$ level. Most of the derivatives were highly effective toward the resistant gastric cell lines, exhibiting an antiproliferative activity comparable to the positive controls cisplatin and etoposide (Table 3, Table S2, Supporting Information). The collateral sensitivity effect (RR $\leq$ $0.5)$ was mostly observed for EPG85-257RDB cells, which are characterized by $\mathrm{ABCB} 1$ overexpression. ${ }^{37}$ With respect to EPG85-257RNOV cells, the best results were obtained for 
A

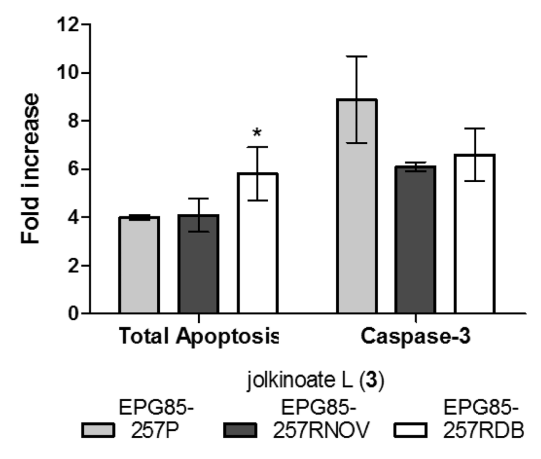

C

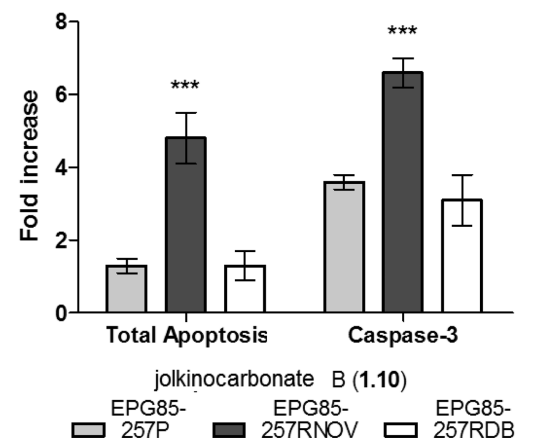

B

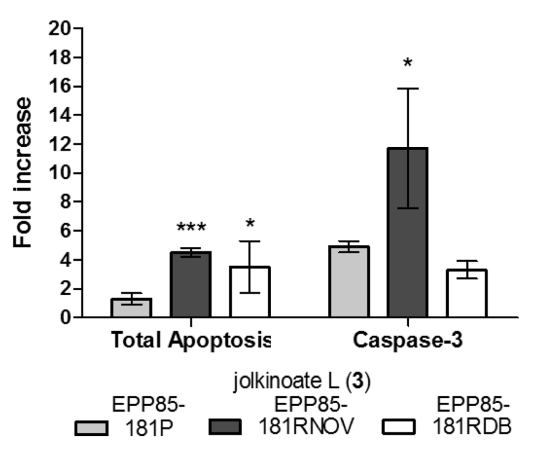

D

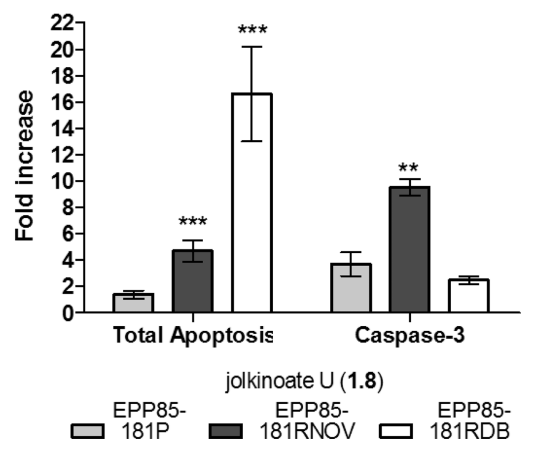

Figure 4. Induction of apoptosis and activation of caspase-3: (A) jolkinoate L (3) in gastric cells; (B) jolkinoate L (3) in pancreatic cells; (C) jolkinocarbonate B (1.10) in gastric cells; and (D) jolkinoate U (1.8) in pancreatic cancer cell lines. Total apoptosis was considered the sum of early and late apoptotic events (cells annexin V positive/PI negative plus cells annexin V positive/PI positive). The results were expressed as the ratio between treated and untreated samples. Each column represents the mean $\pm \mathrm{SD}(n=3)$. Statistical significance was calculated for the difference between treated resistant cell lines and treated parental cells using a two-tailed unpaired Student's $t$ test. $*, p<0.05$. **, $p<0.01$. ***, $p<0.001$.

compounds 1.1, 1.4, 1.8, 1.9, 1.10, and 2.3, which showed $\mathrm{IC}_{50}$ values lower than $10 \mu \mathrm{M}$ (Table 3, Table S2), but only derivatives $\mathbf{1 . 4}$ and $\mathbf{2 . 3}$ showed a collateral sensitivity effect (RR $<0.5)$. Nevertheless, no structure-activity relationships could be inferred for these cell lines. Based on the $\mathrm{IC}_{50}$ and $\mathrm{RR}$ values (Table 3, Table S2), jolkinocarbonate B (1.10) (6.24 \pm 1.08 $\mu \mathrm{M}, 5.55 \pm 0.88 \mu \mathrm{M}$, and $2.34 \pm 0.67 \mu \mathrm{M}$, against EPG85257P, EPG85-257RNOV, and EPG85-257RDB, respectively) was selected for apoptosis induction studies.

Regarding the pancreatic cancer cell lines, the tested compounds were less active (Table 3, Table S3, Supporting Information). Thus, based on $\mathrm{IC}_{50}$ values, only jolkinoate $\mathrm{U}$ (1.8) $(8.61 \pm 0.58 \mu \mathrm{M}$ against EPP85-181P; $6.63 \pm 0.95 \mu \mathrm{M}$ against EPP85-181RNOV; and $5.86 \pm 0.07 \mu \mathrm{M}$ against EPP85181RDB) was chosen for further studies.

Annexin V/PI Assay and Active Caspase-3 Assay. Jolkinoate L (3) showed a remarkable ability to target both gastric and pancreatic MDR contexts. ${ }^{21}$ Likewise, jolkinocarbonate $\mathrm{B}$ (1.10) showed interesting results against gastric cells and jolkinoate $U$ (1.8) against pancreatic cells (Table 3, Tables S1 and S2, Supporting Information). Hence, their ability as apoptosis inducers was evaluated. The annexin V/propidium iodide (PI) assay was used to assess if compounds $3, \mathbf{1 . 8}$, and $1.10(30 \mu \mathrm{M})$ would induce apoptosis. Caspase activation was measured with the active caspase- 3 assays. Detection of these events was performed by flow cytometry after $72 \mathrm{~h}$ exposure. The results of total apoptosis (early and late apoptotic events) and caspase- 3 activation were expressed as fold increase (ratio between treated samples and untreated samples).
Jolkinoate L (3), a trifluormethylbenzoyl derivative, induced apoptosis in the gastric cell lines about 4-fold in EPG85-257P and EPG85-257RNOV, and created a statistically significant 6fold induction in EPG85-257RDB (Figure 4A). Through the caspase-3 data (Figure 4A), it could be concluded that the druginduced cytotoxicity occurred via caspase-mediated apoptosis, since there was a caspase-3 activation of 6-9-fold. On the other hand, jolkinoate L (3) induced significant selective apoptosis in the pancreatic MDR phenotypes EPP85-181RNOV and EPP85-181RDB, in about 4.5- and 3.5-fold, respectively (Figure $4 B)$. In the same way as in the gastric cell lines, the apoptotic process occurred through caspase- 3 activation. Remarkable results were found for EPP85-181RNOV, showing a 12-fold activation of this apoptosis effector protein (Figure 4B).

Moreover, jolkinocarbonate B (1.10) showed a statistically significant apoptosis induction in the gastric EPG85-257RNOV cells, but with little apoptosis induction in EPG85-257P or EPG85-257RDB (Figure 4C). This selective targeting of EPG85-257RNOV cells was corroborated by the caspase-3 activation data (Figure 4C). Although little apoptosis induction was detected for EPG85-257P and EPG85-257RDB cells, caspase- 3 activation was taking place (Figure 4C). Therefore, a quantifiable apoptosis induction may occur after $72 \mathrm{~h}$.

The adamantoyl derivative jolkinoate $U$ (1.8) showed statistically significant selective apoptosis induction between the resistant pancreatic cells (EPP85-181RNOV; EPP85181RDB) and the parental cells; with a 5-fold apoptosis induction on EPP85-181RNOV and a 17-fold induction on EPP85-181RDB. The observed apoptotic processes were 
verified to proceed via caspase- 3 activation, as indicated in Figure 4D.

\section{EXPERIMENTAL SECTION}

General Experimental Procedures. See the Supporting Information.

General Preparation of Derivatives 1.1-1.10 and 2.1-2.4. The detailed preparation and characterization of the derivatives of jolkinol D (1.1-1.10) and of jolkinodiol (2.1-2.4) can be accessed in the Supporting Information.

Rhodamine 123 Accumulation Assay. The mouse T-lymphoma cells L5178Y (ECACC catalogue no. 87111908, U.S. FDA, Silver Spring, MD, USA) and the ABCB1-transfected L5178Y mouse Tlymphoma cells were established and cultured as described. ${ }^{20,38}$ The cells were resuspended in serum-free McCoy's 5A medium in $500 \mu \mathrm{L}$ aliquots adjusted of $2 \times 10^{6} / \mathrm{mL}$. The lathyrane derivatives were added at 2 and $20 \mu \mathrm{M}$, the positive control verapamil (EGIS Pharmaceuticals PLC, Budapest, Hungary) at $20 \mu \mathrm{M}$, and the solvent control DMSO at $2 \%(\mathrm{v} / \mathrm{v})$. The incubation of the samples took place at room temperature for $10 \mathrm{~min}$, after which $10 \mu \mathrm{L}(5.2 \mu \mathrm{M})$ of rhodamine- 123 was added. The samples were washed twice after incubation at $37{ }^{\circ} \mathrm{C}$ for $20 \mathrm{~min}$, resuspended in phosphate-buffered saline $(500 \mu \mathrm{L})$, and analyzed by flow cytometry (Partec CyFlow Space instrument, Partec $\mathrm{GmbH}$, Münster, Germany). The histograms were assessed concerning the mean fluorescence intensity (FL-1), standard deviation, and peak channel of 20,000 individual cells belonging to the total and gated populations. The fluorescence activity ratio (FAR) was calculated as FAR $=\left(\right.$ L5178Y-MDR $\left.\mathrm{FL}_{\text {-1 treated }} / \mathrm{L} 5178 \mathrm{Y}-\mathrm{MDR}_{\mathrm{FL}-1 \text { control }}\right) /$ $\left(\mathrm{PAR}_{\mathrm{FL}-1 \text { treated }} / \mathrm{PAR}_{\mathrm{FL}-1 \text { control }}\right)$.

ATPase Assay. The SB-MDR1 PREADEASY ATPase Kit (SOLVO Biotechnology, Szeged, Hungary) was preformed according to the manufacturer's instructions. The purified Sf9 insect membrane vesicles ( $4 \mu \mathrm{g}$ protein/well), expressing high levels of human MDR1, were incubated in $50 \mu \mathrm{L}$ of ATPase assay buffer, compound, and 2 $\mathrm{mM}$ MgATP, for $10 \mathrm{~min}$ at $37^{\circ} \mathrm{C}$. The final concentration of DMSO in the experiment was $2 \%(\mathrm{v} / \mathrm{v})$. The ATPase reaction was stopped, and the inorganic phosphate $(\mathrm{Pi})$ production was measured colorimetrically (optical density was read at $630 \mathrm{~nm}$ ). The amount of $\mathrm{Pi}$ produced is proportional to the ABCB1 activity. Hence, ATPase activities were determined as the difference of the measured $\mathrm{Pi}$ liberation with and without the presence of $1.2 \mathrm{mM}$ sodium orthovanadate (vanadate-sensitive ATPase activity). This ATPase kit comprises two different tests: the activation and inhibition assays. When the test compound can stimulate the baseline vanadate-sensitive ATPase activity (activation assay), it reflects the ABCB1 transported, as is the case of verapamil $(40 \mu \mathrm{M})$, used as positive control. The inhibition assay assesses the effect of a second transported substrate on ABCB1 ATPase activity. Thus, the compounds are tested in the presence of verapamil $(40 \mu \mathrm{M})$. Inhibitors of $A B C B 1$ may reduce the verapamil-stimulated vanadate-sensitive ATPase activity. In some cases, inhibitors may inhibit the baseline transporter ATPase activity as well, such as cyclosporine $\mathrm{A}(40 \mu \mathrm{M})$, also used as positive control.

Antiproliferative Assay and Drug Combination Studies. The antiproliferative assay was performed according to a published procedure. $^{20}$ The parental (PAR) and multidrug-resistant (MDR) ABCB1-transfected L5178Y mouse T-lymphoma cells were seeded at 1 $\times 10^{5} / \mathrm{mL}$ and incubated with a concentration gradient of compounds (final volume of $200 \mu \mathrm{L} /$ well $)$ for $72 \mathrm{~h}\left(5 \% \mathrm{CO}_{2}\right.$ at $\left.37^{\circ} \mathrm{C}\right)$. The final concentration of DMSO in the experiment was $1 \%(\mathrm{v} / \mathrm{v})$. Cell growth was determined by measuring the optical density (OD) at $550 \mathrm{~nm}$ (ref $630 \mathrm{~nm}$ ) with a Multiscan EX ELISA reader (Thermo Labsystems, Cheshire, WA, USA $)$; and determined as $100-\left[\left(\mathrm{OD}_{\text {sample }}-\right.\right.$ $\left.\left.\mathrm{OD}_{\text {mediumcontrol }}\right) /\left(\mathrm{OD}_{\text {cellcontrol }}-\mathrm{OD}_{\text {mediumcontrol }}\right)\right] \times 100$. Mean $\mathrm{IC}_{50}$ values were obtained from three independent experiments for each cell line, by best fitting the dose-dependent inhibition curves in the GraphPadPrism5 program.

Drug combinations of doxorubicin (Teva) and the compounds were designed and evaluated according to Chou using the software CalcuSyn Version 2.34,35 Since the optimal concentration range for the combination is not known, the most appropriated experimental design is by using several concentrations of each agent, with data points above and below $\mathrm{IC}_{50}$. The experimental design followed the checkerboard microplate method, where dilutions of doxorubicin were made in a horizontal direction and the dilutions of resistance modifiers vertically in a microtiter plate to a final volume of $200 \mu \mathrm{L}$ of medium per well. The L5178Y-MDR cells were distributed at $2 \times 10^{5}$ cells $/ \mathrm{mL}$ per well and were incubated for $48 \mathrm{~h}$ under standard conditions. The cell growth rate was determined after MTT staining, as previously described. ${ }^{20}$ Each drug combination produces an effect, and constant ratios ([compound]/[doxorubicin]) can be taken from the diagonals of the checkerboard. The effect of each constant ratio across a concentration gradient was computed in CalcuSyn software. More details concerning the CalcuSyn model and combination index calculation can be assessed in the Supporting Information.

Collateral Sensitivity Assays: Antiproliferative Assay. Cell culture procedures of the human carcinoma cell lines (EPG85-257P and EPP85-181P) and their drug-resistant sublines (EPG85257RNOV, EPG85-257RDB, EPP85-181RNOV, EPP85-181RDB) have been described previously. ${ }^{21}$ Briefly, $5 \times 10^{3} / \mathrm{mL}$ (EPG85-257P and EPP85-181P) and $7.5 \times 10^{3} / \mathrm{mL}$ (EPG85-257RNOV, EPG85257RDB, EPP85-181RNOV, EPP85-181RDB) were seeded. After attachment $(48 \mathrm{~h})$, the compounds were added in a dilution series for incubation during 5 days $\left(5 \% \mathrm{CO}_{2}\right.$ at $\left.37^{\circ} \mathrm{C}\right)$. The final concentration of DMSO in the experiment was $0.3 \%(\mathrm{v} / \mathrm{v})$. Cell growth was based on sulforhodamine B (SRB) staining and was performed according to a published procedure. ${ }^{21}$ Cell growth was measured at $562 \mathrm{~nm}$ against the reference wavelength of $690 \mathrm{~nm}$. Mean $\mathrm{IC}_{50}$ values were obtained from three to four independent experiments in triplicate for each cell line, by best fitting the dose-dependent inhibition curves in the GraphPadPrism5 program. Relative resistance (RR) values were calculated as $\mathrm{IC}_{50 \text { (resistant cells) }} / \mathrm{IC}_{50 \text { (parental cells) }}$.

Annexin V/PI Staining and Active Caspase-3 Assay. An FITC Annexin V apoptosis detection kit (BD Pharmingen, BD Biosciences) was used to detect cytotoxic drug-induced apoptosis. The intracellular presence of active caspase- 3 was detected using an FITC Active Caspase-3 Apoptosis Kit (BD Pharmingen, BD Biosciences). Both assays followed the same experimental design. Briefly, $6 \times 10^{4} \mathrm{cell} / \mathrm{mL}$ of parental cell lines (EPG85-256P and EPP85-181P) and $1 \times 10^{5}$ cell/mL of resistant cell lines (EPG85-256RNOV, EPG85-256RDB, EPP85-181RNOV, and EPP85-181RDB) were seeded in six-well plates in complete medium and attached for $24 \mathrm{~h}$. The medium was thrown away the next day, and new medium (with $30 \mu \mathrm{M}$ of compounds) was added to the cancer cells. The final concentration of DMSO in the experiment was $0.3 \%(\mathrm{v} / \mathrm{v})$. Camptothecin (Cayman Chemicals, Ann Arbor, Michigan, USA) was used as positive control $(1 \mu \mathrm{M})$. Cells were further incubated for $72 \mathrm{~h}\left(5 \% \mathrm{CO}_{2}, 37^{\circ} \mathrm{C}\right)$. The concentration of compounds and positive control, and incubation time were optimized in order to ensure a good sampling for flow cytometry measurement of the apoptotic process (data not shown). After this incubation period, cells were trypsinized, washed in PBS, and stained according to each kit manufacturer's instructions. Stained cells were analyzed using a BD Accuri C6 flow cytometer (BD Pharmingen, BD Biosciences), and data were processed with $\mathrm{BD}$ Accuri $\mathrm{C} 6$ software. Each sample was assessed using a collection of 10000 events. The mean values and standard deviations were calculated from three independent experiments.

Statistical Analysis. K-means clustering, which subdivides the compounds (those with the nearest mean) into groups that exhibit a high degree of similarity, was performed with Tanagra, version 1.4.41 (https://eric.univ-lyon2.fr/ ricco/tanagra/). Statistical evaluation of the apoptosis assays data was performed with the two-tailed unpaired Student's $t$ test using GraphPadPrism5 software. Probability value $p<$ 0.05 was considered statistically significant. 


\section{ASSOCIATED CONTENT}

\section{S Supporting Information}

The Supporting Information is available free of charge on the ACS Publications website at DOI: 10.1021/acs.jnatprod.6b01084.

Methods; antiproliferative activity against mouse Tlymphoma cells and against pancreatic and gastric cell lines; ${ }^{1} \mathrm{H}$ and ${ }^{13} \mathrm{C}$ NMR spectra; and flow cytometry data. (PDF)

\section{AUTHOR INFORMATION}

\section{Corresponding Author}

*Tel: +351217946475. Fax: +351217946470. E-mail: mjuferreira@ff.ulisboa.pt.

\section{ORCID}

Mariana A. Reis: 0000-0001-8737-2138

Maria-José U. Ferreira: 0000-0002-8742-1486

\section{Present Addresses}

"(M.A.R.) Interdisciplinary Centre of Marine and Environmental Research (CIIMAR/CIMAR), University of Porto, Terminal de Cruzeiros do Porto de Leixões, Avenida General Norton de Matos, S/N, 4450-208 Matosinhos, Portugal.

${ }^{\perp}$ (H.L.) Department of Pathology, Vivantes Clinics, Berlin, Germany.

Notes

The authors declare no competing financial interest.

\section{ACKNOWLEDGMENTS}

This study was financially supported by Fundação para a Ciência e a Tecnologia (FCT), Portugal (project PTDC/QEQMED/0905/2012; PhD grant SFRH/BD/72915/2010), German Egyptian Research Long-term Scholarship (GERLS) Program 2014 (57076387) provided by the German Academic Exchange Service (DAAD), and the contribution of the Foundation for Cancer Research Szeged, Hungary. We also acknowledge Carlos Cordeiro, Faculdade de Ciências, Universidade de Lisboa, for HRMS data (FCT, REDE/1501/ REM/2005).

\section{REFERENCES}

(1) Ferlay, J.; Soerjomataram, I.; Dikshit, R.; Eser, S.; Mathers, C.; Rebelo, M.; Parkin, D. M.; Forman, D.; Bray, F. Int. J. Cancer 2015, 136, E359-E386.

(2) Lage, H. Cell. Mol. Life Sci. 2008, 65, 3145-3167.

(3) Gottesman, M. M.; Lavi, O.; Hall, M. D.; Gillet, J.-P. Annu. Rev. Pharmacol. Toxicol. 2016, 56, 85-102.

(4) Holohan, C.; Van Schaeybroeck, S.; Longley, D. B.; Johnston, P. G. Nat. Rev. Cancer 2013, 13, 714-726.

(5) Kartal-Yandim, M.; Adan-Gokbulut, A.; Baran, Y. Crit. Rev. Biotechnol. 2016, 8551, 1-11.

(6) Gottesman, M. M.; Fojo, T.; Bates, S. E. Nat. Rev. Cancer 2002, 2, $48-58$.

(7) Callaghan, R.; Luk, F.; Bebawy, M.; Cuperus, F. J. C.; Claudel, T.; Gautherot, J.; Halilbasic, E.; Trauner, M. Drug Metab. Dispos. 2014, 42, 623-631.

(8) Szakács, G.; Hall, M. D.; Gottesman, M. M.; Boumendjel, A.; Kachadourian, R.; Day, B. J.; Baubichon-Cortay, H.; Di Pietro, A. Chem. Rev. 2014, 114, 5753-5774.

(9) Szybalski, W.; Bryson, V. J. Bacteriol. 1952, 64, 489-499.

(10) Hall, M. D.; Handley, M. D.; Gottesman, M. M. Trends Pharmacol. Sci. 2009, 30, 546-556.

(11) Pluchino, K. M.; Hall, M. D.; Goldsborough, A. S.; Callaghan, R.; Gottesman, M. M. Drug Resist. Updates 2012, 15, 98-105.
(12) Harvey, A. L.; Edrada-Ebel, R; Quinn, R. J. Nat. Rev. Drug Discovery 2015, 14, 111-129.

(13) Newman, D. J.; Cragg, G. M. J. Nat. Prod. 2007, 70, 461.

(14) Ferreira, R. J.; Dos Santos, D. J. V.; Ferreira, M. J. U.; Guedes, R. C. J. Chem. Inf. Model. 2011, 51, 1315-1324.

(15) Reis, M.; Ferreira, R.; Serly, J.; Duarte, N.; Madureira, A. M.; Santos, D. J. V.; Molnar, J.; Ferreira, M. J. U. Anti-Cancer Agents Med. Chem. 2012, 12, 1015-1024.

(16) Sousa, I. J.; Ferreira, M. J. U.; Molnár, J.; Fernandes, M. X. Eur. J. Pharm. Sci. 2013, 48, 542-553.

(17) Vieira, C.; Duarte, N.; Reis, M. A.; Spengler, G.; Madureira, A. M.; Molnár, J.; Ferreira, M. J. U. Bioorg. Med. Chem. 2014, 22, 63926400.

(18) Matos, A. M.; Reis, M.; Duarte, N.; Spengler, G.; Molnár, J.; Ferreira, M. J. U. J. Nat. Prod. 2015, 78, 2215-2228.

(19) Baptista, R.; Ferreira, R. J.; Dos Santos, D. J.; Fernandes, M. X.; Ferreira, M. J. U. Future Med. Chem. 2016, 8, 629-645.

(20) Reis, M.; Ferreira, R. J.; Santos, M. M.; Dos Santos, D. J. V.; Molnár, J.; Ferreira, M. J. U. J. Med. Chem. 2013, 56, 748-760.

(21) Reis, M. A.; Paterna, A.; Ferreira, R. J.; Lage, H.; Ferreira, M. J. U. Bioorg. Med. Chem. 2014, 22, 3696-3702.

(22) Lage, H.; Duarte, N.; Coburger, C.; Hilgeroth, A.; Ferreira, M. J. U. Phytomedicine 2010, 17, 441-448.

(23) Hilgeroth, A.; Baumert, C.; Coburger, C.; Seifert, M.; Krawczyk, S.; Hempel, C.; Neubauer, F.; Krug, M.; Molnár, J.; Lage, H. Med. Chem. 2013, 9, 487-493.

(24) Das, R; Chakraborty, D. Synthesis 2011, 2011, 1621-1625.

(25) Voigt, B.; Coburger, C.; Monár, J.; Hilgeroth, A. Bioorg. Med. Chem. 2007, 15, 5110-5113.

(26) Jiao, W.; Wan, Z.; Chen, S.; Lu, R.; Chen, X.; Fang, D.; Wang, J.; $\mathrm{Pu}$, S.; Huang, X.; Gao, H.; Shao, H. J. Med. Chem. 2015, 58, 37203738.

(27) Chufan, E. E.; Sim, H.; Ambudkar, S. V. In Adv. Cancer Res.; Elsevier Inc., 2015; pp 71-96.

(28) Ambudkar, S. V.; Dey, S.; Hrycyna, C.; Ramachandra, M.; Pastan, I.; Gottesman, M. M. Annu. Rev. Pharmacol. Toxicol. 1999, 39, 361-398.

(29) Dongping, M. Promega Notes 2007, 11-14.

(30) Ledwitch, K. V.; Gibbs, M. E.; Barnes, R. W.; Roberts, A. G. Biochem. Pharmacol. 2016, 118, 96-108.

(31) Calabrese, E. J. Crit. Rev. Toxicol. 2008, 38, 473-487.

(32) Chufan, E. E.; Sim, H.-M.; Ambudkar, S. V. Adv. Cancer Res. 2015, 125, 71-96.

(33) Zinzi, L.; Capparelli, E.; Cantore, M.; Contino, M.; Leopoldo, M.; Colabufo, N. A. Front. Oncol. 2014, 4, 1-12.

(34) Chou, T.-C. Cancer Res. 2010, 70, 440-446.

(35) Chou, T.-C. Pharmacol. Rev. 2006, 58, 621-681.

(36) Szakács, G.; Paterson, J. K.; Ludwig, J. a; Booth-Genthe, C.; Gottesman, M. M. Nat. Rev. Drug Discovery 2006, 5, 219-234.

(37) Dietel, M.; Arps, H.; Lage, H.; Niendorf, A. Cancer Res. 1990, $50,6100-6106$

(38) Pastan, I.; Gottesman, M. M.; Ueda, K.; Lovelace, E.; Rutherford, V.; Willingham, M. C. Proc. Natl. Acad. Sci. U. S. A. 1988, 85, 4486-4490. 